\title{
Role of therapeutic phlebotomy in management of case of porphyria cutanea tarda (PCT) admitted in tertiary care hospital Vadodara
}

\begin{abstract}
Porphyria cutanea tarda is the most frequent type of Porphyria worldwide \& presents with skin symptoms mainly. Porphyrias can affect peripheral, autonomic and central nervous system. In Porphyria conditions there is accumulation of heme precursors 5 Aminolevulinic acid, Porphobilinogen and porphyrins which are associated with characteristic clinical feature with acute neurovisceral attacks and skin lesions. This case report summarizes Case of PCT that was successfully managed with Therapeutic Phlebotomy.
\end{abstract}

Keywords: porphyria cutanea tarda, skin lesions, therapeutic phlebotomy
Volume 8 Issue I - 2020

\author{
Ashu Dogra \\ Sumandeep University,Vadodara, India
}

Correspondence: Ashu Dogra, Sumandeep University, Vadodara, Opposite post office Muthi, Jamnu, India, Tel 0997930442I,Email drashudogr@yahoo.com

Received: November II, 2019 | Published: January 3I, 2020

\section{Background}

The Porphyrias are a rare group of metabolic disorders that can either be inherited or acquired. Along the heme biosynthetic Pathway, Porphyrias can manifest with neurovisceral or cutaneous symptoms depending on the defective enzyme.Porphyria cutanea tarda, the most common type of Porphyrias worldwide, is caused by a deficiency of uroporphyrinogen decarboxylase, a crucial enzyme in heme biosynthesis, which results in accumulation of photosensitive by products, such as uroporphyrinogen, which leads to the fragility and blistering of sun exposed skin. ${ }^{1}$

Porphyria cutanea tarda is the most common type of Porphyria in humans. Estimates Prevalence have ranged from 1 in 5000 to 25000 People. Porphyria cutanea tarda (PCT) is characterised clinically by photosensitive dermatosis associated with skin fragility and blistering. The cutaneous photosensitivity is mediated by uroporphyrin and partially decarboxylated porphyrins. The source of these compounds is liver where activity of uroporphyrinogen decarboxylase is diminished. The compounds accumulate in liver, circulate in plasma, and are excreted in urine. ${ }^{2}$

Since it was first described by Waldenstrom in 1937, there has been increasing interest in the relationship between Porphyria cutanea tarda (PCT), iron overload, UROD activity and the possible link to hereditary hemochromatosis. ${ }^{3}$ The disorder usually starts after 30 years of age and childhood occurrence is rare. Although it is an acquired disease sometimes it is genetic. ${ }^{4}$

The low Uroporphyrinogen-decarboxylase activity in PCT promoted its subdivision as follows:-

1. Sporadic Porphyria cutanea tarda ( type I, symptomatic or acquired)

2. Familial Porphyria cutanea tarda (Type II or inherited)

3. Type III Porphyria cutanea tarda

4. Toxic Porphyria cutanea tarda
5. Environmental factors also play a role. Leading environmental factors are alcohol usage and presence of Hepatitis C or HIV. Certain medications like estrogen and cytochrome P- 450 inhibitors, tobacco are also involved. All these factors are thought to decrease hepcidin levels in the body and cause iron storage in liver. ${ }^{5}$

\section{Case presentation}

A 37 Year old male presented to skin and Venereal disease department with Chief Complaints of fatigue, breathlessness, eczematoid blistering eruptions on hands, hypertrichosis of face which occurred after exposure to sun followed by blister formation and development of scar (Figure 1). Family history was positive for Porphyria cutanea tarda (PCT). Elder brother K/C/O Porphyria cutanea tarda (PCT) died recently due to associated complications. UROD mutation studies in patient were not carried out due to financial strains. The patient is abstainer from alcohol and smoking.

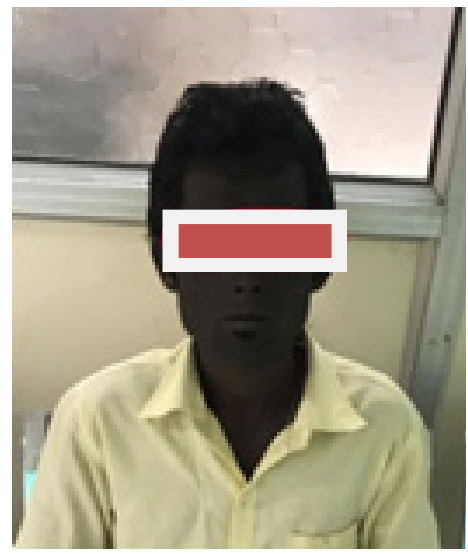

Figure I Skin involvement of Porphyria cutanea tarda: Hypertrichosis of Face in Patient of Porphyria Cutanea Tarda.

On physical examination face and dorsum of hands had brown pigmented skin lesions. His (BMI) Body Mass Index was $35 \mathrm{~kg} / \mathrm{m}^{2}$. 
Patient serum showed red fluorescence to UV light. His Pathological lab results showed there was increase in polymorphs count and decreased lymphocyte count. The SGOT 150 u/l (normal 0-50), SGPT $95 \mathrm{u} / 1$ (normal ), gammaglutamyl transferase 1000u/1, Lactate dehydrogenase (LDH ) 300 (normal 0-248) Creatinine kinase 170u/l (normal 0-171), Alkaline Phosphatase 85u/l, S. Ferritin 199ng/ml (normal 20-250ng/ml), vitamin B12 levels $1200 \mathrm{pg} / \mathrm{ml}($ normal 145914) (Table 1). Serological tests for Hepatitis B, Hepatitis C, HIV were negative.

His porphyrin levels in urine was 750 micrograms/24 hours (normal $\leq 100$ ), his porphobilinogen levels was $1.65 \mathrm{mg} / 24$ hours (normal is $\leq$ to 1.65). The clinical history of Patient, his laboratory investigations, typical skin lesions are all consistent with diagnosis of PCT.

Therapeutic Phlebotomy was started as treatment regime. Whole Blood removed at rate of $8 \mathrm{ml} / \mathrm{kg}$ body weight and replaced with approximately equal volume of crystalloid fluid mainly Ringer lactate. Frequency of therapeutic phlebotomy was every 2 weeks decided till serum ferritin levels reached around lower limit of normal range. Total of 5 therapeutic phlebotomy were performed after which his symptoms regressed and laboratory values too reached normal ranges with serum ferritin being reported as $45 \mathrm{ng} / \mathrm{ml}$

Table I Lab investigation details

\begin{tabular}{|c|c|c|}
\hline Clinical parameter & $\begin{array}{l}\text { Value observed from patient } \\
\text { blood sample }\end{array}$ & Normal value \\
\hline Hemoglobin & $|\lg / d|$ & $14-18 \mathrm{~g} / \mathrm{dl}$ \\
\hline Total count & $2 \times 103 \mathrm{cells} / \mathrm{cu} \mathrm{mm}$ & 4 to 11000 \\
\hline \multicolumn{3}{|l|}{ Differential count } \\
\hline Polymorphs & $90 \%$ & $40-70$ \\
\hline Lymphocytes & $7 \%$ & $20-40$ \\
\hline Platelet count & $501 \times 10^{3} / \mathrm{cu} \mathrm{mm}$ & I.5-4.5 lakhs/cu.mm \\
\hline Red blood cells & $5 \times 106 / \mathrm{mm}^{3}$ & $4-6.50$ \\
\hline Hematocrit & $33 \%$ & $35-55$ \\
\hline Mean cell volume & $78 f \mathrm{f}$ & $80-100 F I$ \\
\hline Mean cell haemoglobin & 25PG/CELL & 27-32pg \\
\hline Mean cell hemoglobin concentration & $30 g / d l$ & \\
\hline SGOT & I20u/I & $0-35 \mathrm{u} / \mathrm{l}$ \\
\hline SGPT & $98 u / l$ & $0-50 \mathrm{u} / \mathrm{l}$ \\
\hline GGT & I000u/l & $0-55$ \\
\hline Alkaline phosphatise & 85 & $30-120 \mathrm{IU}$ \\
\hline Serum creatinine & $0.8 \mathrm{mg} / \mathrm{dl}$ & \\
\hline Serum ferritin & I99ng/ml & $20-250 \mathrm{ng} / \mathrm{ml}$ \\
\hline
\end{tabular}

\section{Discussion}

PCT is relatively rare disease in India. The susceptible factors responsible for aggravation of disease include ethanol intake, smoking, Hepatitis $\mathrm{C}$ virus infection, HIV infection, UROD mutation. Mechanism of HCV and alcohol abuse causing PCT is postulated due to suppression of hepcidin expression leading to iron overload and increase in oxidative stress in liver. ${ }^{6}$

In PCT large amounts of Porphyrins get accumulated in liver over a period of few months. ${ }^{7}$ PCT is a metabolic disorder which can result in development of Hepatocellular carcinoma, advanced liver fibrosis and also liver cirrhosis if cutaneous manifestations are not recognized and properly investigated. The diagnosis of PCT depends on the definition of characteristic symptoms, a detailed history, clinical evaluation and special tests (blood test, urine test, stool test and skin biopsy). An increase in uroporphyrin and hepatocarboxyl porphyrin levels in urine is important for diagnosis.

PCT treatment targets specific symptoms of patients. The standard treatment of PCT is regular Phlebotomy and medications like hydroxychloroquine to decrease iron and porphyrin levels in liver. In our case though patient was given low dose hydroxychloroquine but no improvement in his symptoms was noted. Porphyria cutanea tarda patients with hemochromatosis are reportedly resistant to chloroquine and are more appropriately treated by phlebotomy. ${ }^{8}$ Therapeutic phlebotomy with suggested approach to make a phlebotomy of one whole blood unit $(450 \mathrm{ml})$ every 2 weeks until ferritin level reaches lower limit of normal range of ferritin proved successful. Regularly performed phlebotomies cause full remission in most cases. Usually 5-8 phlebotomies are needed to achieve full remission Care should be taken to not induce anemia (Hemoglobin $<10-11 \mathrm{~g} / \mathrm{dl}$ ). 
Patients with PCT are suggested to quit smoking tobacco and alcohol intake as these might trigger their disease. They should avoid direct exposure to the sun using double layer of clothing, wide hats, gloves and sun glasses. Full remission is possible with treatment of PCT but relapse is possible. Relapse treatment is same as primary treatment. Genetic counselling is advised for familial type of PCT. As the risk for developing PCT in other family members is somewhat increased, asymptomatic carriers should be advised to avoid susceptibility factors such as heavy alcohol use, smoking and oral estrogens.

\section{Conclusion}

Porphyria cutanea tarda patients should be closely monitored for clinically, biochemically and for their response to treatment. Therapeutic phlebotomy has been found to be one of effective treatment modality when combined with avoidance of precipitating factors.

\section{Acknowledgments}

None.

\section{Conflicts of interest}

Authors declare that there is no conflict of interest in our article.

\section{References}

1. Usta Atmaca H, Akbas F. Porphyrea cutanea tarda: a case report. J Med Case Rep. 2019;13(1):17.

2. Bulaj ZJ, Phillips JD, Ajioka RS, et al. Hemochromatosis genes and other factors contributing to the pathogenesis of porphyria cutanea tarda. Blood. 2000;95(5):1565-1571.

3. Frank J, Poblete- Gutierrez P. Porphyria cutanea tarda- when skin meets liver. Best Pract Res Clin Gastroenterol. 2010;24(5):735-7445.

4. Elder GH. Porphyrea cutanea tarda and related disorders. Chapter 88 . In: Kadish KM, Smith K, editors. Porphyrin Handbook Part II Vol 14. San Diego: Academic Press; 2003. p. 67-92.

5. Schmid R. Cutaneous Porphyria in Turkey. NEngl J Med. 1960;263:397398.

6. BS Roopa, R Gurumoorthi, Ponnusankar Sivasankaran. Porphyria cutanea tarda: A rare metabolic condition in India. International Journal of health and allied sciences. 2015;4(2):108-110.

7. Puy H, Gouyal L, Deybach JC. Porphyrias. Lancet. 2010;375:924-937.

8. Singal AK, Kormos-Hallberg C, Lee C, et al. Low dose hydroxychloroquine is as effective as phlebotomy in treatment of patients with porphyria cutanea tarda. Clin Gastroenterol Hepatol. 2012;10(12):1402-1409. 